\title{
BACKGROUND CHARACTERISTICS AND RESPONSES TO TREATMENT OF TWO TYPES OF INSTITUTIONALIZED DELINQUENT BOYS
}

\author{
MARTIN GOLD \\ University of Michigan \\ JAY MATTLIN \\ Temple University \\ D. WAYNE OSGOOD \\ University of Nebraska, Lincoln
}

Two types of institutionalized delinquent boys were identified in a sample of 306 for the purpose of investigating differences in the etiology of their antisocial behavior and in their responses to a group-centered treatment program. The "Buoyant" and "Beset" types, defined by their levels of anxiety and depression, are compared conceptually to types identified in other classification schemes. Two-thirds of the sample showed sufficiently stable anxiety and depression over time to warrant classification. The importance of considering stability in defining the types is underscored by comparisons of the stable with unstable boys. Comparison of the Buoyant and Beset types revealed significant differences in life experiences and style of delinquent behavior prior to their institutionalization, in their behavior and attitudes during incarceration, and in the components of the treatment that affected their behavior and attitudes. The findings are discussed in terms of the validity of the proposed typology, their implications for etiological theory, and the guidance they may provide for differential treatment.

$\mathbf{T}$ his article reports a study intended to assess the usefulness of a particular typology of delinquent boys. The typology

\footnotetext{
AUTHORS' NOTE: This research was supported by the NIMH Center for Studies of Antisocial and Violent Behavior, Grant No. MH34065, by the Michigan Office of Criminal Justice, Grant No. 83771-1R85, and by the Edna McConnell Clark Foundation, Grant No. 282-0056. The authors thank

CRIMINAL JUSTICE AND BEHAVIOR, Vol. 16 No. 1, March 1989 5-33

๑ 1989 American Association for Correctional Psychology
} 
is grounded in a general theory of delinquent behavior that conceives of delinquency as a defense that many adolescents employ successfully to ward off conscious feelings of selfderogation (Gold \& Mann, 1972). A variety of studies, using different methods and observing different samples of adolescents, support the conclusion that low self-esteem motivates delinquent behavior (Gold \& Mann, 1972; Kaplan, 1980; Shore \& Massimo, 1969). The typology is based on the observation that some heavily delinquent youth continue to display low self-esteem. This persistent self-derogation indicates that delinquency is an inadequate defense for these youth, and, as a consequence, they should experience high levels of anxiety and depression.

In this study, we investigate whether distinguishing institutionalized delinquent boys on the basis of their anxiety and depression constitutes a useful typology. We assess the validity of the typology in terms of its relationships to background characteristics of youth and to their responsiveness to a group-centered treatment program. We take advantage of a short-term longitudinal design to distinguish delinquents whose anxiety and depression seem to be stable personal attributes from those whose anxiety and depression is more variable, and presumably more responsive to situational factors.

The anxious and depressed youth are the type of delinquents that Hewitt and Jenkins (1947) labeled "unsocialized aggressive" and distinguished from "socialized" delinquents in their classic typological study. (Hewitt and Jenkins actually claimed to have found three "fundamental patterns of maladjustment," of which only these two were specifically delinquent.) Hewitt and Jenkins's typology is based on an assessment of enduring personal characteristics. In this respect, it is more similar to the personality-based typological approaches of researchers such as Lykken (1957),

Dr. Herbert C. Quay and Dr. Allen K. Hess for their helpful comments on earlier drafts. The authors' names are listed alphabetically to indicate equal coauthorship. Correspondence concerning this article may be addressed to Martin Gold, Research Center for Group Dynamics, University of Michigan, Ann Arbor, MI 48106-1248. 
Quay (1964), Eysenck (1970), Hare (1970), and Megargee and Bohn (1979) than to those whose classifications are based on the kinds of offenses the delinquents committed (e.g., Hindelang \& Weis, 1972; McCord, McCord, \& Zola, 1959) or on the social milieu in which offenders live (e.g., Cloward \& Ohlin, 1960).

Hewitt and Jenkins's typology has held up well in subsequent research. (See Gold \& Petronio, 1980, and Quay, 1987, for reviews of studies.) Hewitt and Jenkins (1947) labeled their two delinquent types "unsocialized" and "socialized" on account of the differences in their relations with peers. They found the former to be more quarrelsome, unable to get along with other children, and lacking close friends. The corresponding "undersocialized aggressives" in Quay's (1987, p. 121) scheme are also characterized by poor interpersonal relations and are "likely to be at odds with everyone in the environment." In a separate line of research, Lykken (1957) also found that young adult criminals could be usefully typed on the basis of the degree of their anxiety, the less anxious showing less avoidance of punished responses during a test of avoidance learning.

Our version of the typology originates in Gold and Mann's (1984) study of the effectiveness of alternative school programs. They distinguished only two types of delinquents, using a measure of anxiety and depression to classify the boys and girls they observed. Gold and Mann recognized the similarity of their typology to Hewitt and Jenkins's and to Quay's. They labeled their types "Beset" and "Buoyant" in order to call attention to the emotional condition by which the youths were classified, rather than to assume any particular differences in their peer relations. The Beset are like Hewitt and Jenkins's unsocialized type and probably includes both Quay's undersocialized and anxiouswithdrawn-dysphoric types. It should be noted here that, of these two types, Hewitt and Jenkins (1947, p. 95) found the unsocialized aggressive to be more "neurotic" and "nervous," but not more "depressed." In comparison to the Buoyant youth, the Beset were not only more anxious and depressed, but Gold and Mann also found that they got along worse with their peers and tended to 
commit more solitary delinquent acts, thus conforming to the "unsocialized" description of Hewitt and Jenkins.

The theoretical and empirical differences between the two types led us to hypothesize that they would differ in their lifehistories and other personal characteristics. Hewitt and Jenkins believed that the two types had been treated differently by their parents: They observed that the unsocialized aggressives were rejected from infancy, while loss of control by parents during adolescence was typical of the socialized aggressives. In an English replication of Hewitt and Jenkins's study, however, Field (1967) found no relationship of the three types to any particular type of upbringing.

Types based on Hewitt and Jenkins's system have also been found to differ in their responsiveness to treatment. Quay (1987, p. 128) has concluded, "It is abundantly clear that the Undersocialized Aggressive group is the most troublesome in the institutional setting ..." and that "failure while on probation [is] more common among this group." Gold and Mann (1984) reported that an alternative school program had a positive effect on Buoyant youth, but not on Beset youth. Atwood, Gold, and Taylor (in press), in a preliminary analysis of data on the boys included in the present study, found that the Beset boys did not respond as well to group-oriented institutional programs as their Buoyant fellows did four months after they had been admitted to the institution. The boys' scores on the measure of anxiety and depression administered upon their admission predicted reliably to several measures of institutional adjustment four months later.

Rubinstein (1986) addressed two important methodological issues pertaining to the Buoyant/Beset typology. One is whether grouping delinquents into types is more appropriate than treating anxiety and depression as a continuous dimension. His cluster analyses of delinquent boys' profiles on Gold and Mann's scale of anxiety and depression yielded a simple dichotomy between the highs and the lows; any further subclassification blurred the distinctiveness of the two types.

The other issue addressed by Rubinstein is whether the anxiety and depression by which the delinquents were classified in the studies by Gold and Mann (1984) and by Atwood et al. 
characterize merely their mood as interviewees. Rubinstein casts doubt on this narrow interpretation, for he found that the Beset more than the Buoyant boys were described independently by their caregivers as emotionally disturbed.

Thus previous research suggests that a typology that distinguishes delinquents on the basis of the degree of their anxiety and depression is a promising one, both to investigate the lifehistorical conditions for their delinquency and to predict their responses to treatment programs. Such a typology is similar to others that have emerged since Hewitt and Jenkins's pathbreaking work, although in some ways it is more focused. It is made up simply of two types rather than three or four, but seems nevertheless as strongly related to background and outcome variables as more numerously divided typologies. In addition, the theoretical and operational definition upon which it restsanxiety and depression - may be the essence of a major motive for delinquent behavior, and whether delinquents are conscious of their anxiety and depression may be largely responsible for their different responses to treatment. Because it reflects the defining characteristics of the level of anxiety and depression, the terms used in this article follow Gold and Mann (1984). We call the less anxious and depressed "Buoyant," and the more anxious and depressed "Beset."

Two sets of hypotheses guided this study. One concerns the life-histories of the delinquent respondents; the other, their adjustment to the group-oriented institutional treatment programs to which they were committed.

According to our theory, the Beset delinquents suffer from low self-esteem due to personal difficulties that are too deep seated to be resolved by engaging in delinquent behavior. Therefore, we expected that they would be more likely to have experienced events that could interfere with normal socio-emotional development. So we hypothesized that the Beset boys would show a greater incidence of broken homes and separation from the primary caregiver. We also hypothesized that Buoyant delinquents would have committed more of their delinquent acts in the company of others, because their self-esteem is maintained by an audience of peers who applaud their delinquent behavior. 
As to their responses to treatment, we expected that the Beset would not adjust as well to group-oriented programs as the Buoyant boys would because they get along less well with peers. Furthermore, we expected that the two types would respond differently to certain variations in programs. One dimension of variation is the degree of autonomy boys are given by the staff and members of their group, that is, the extent they feel they have control over what happens to them at the institution. In prior research on the present sample, Osgood and his associates (Atwood \& Osgood, 1987; Osgood, Gruber, Archer, \& Newcomb, 1985; Martin \& Osgood, 1987) have found that greater autonomy was generally conducive to the boys' institutional adjustment. Because they would generally feel less put upon and more in control of themselves than the Beset boys would, we hypothesized that the Buoyant boys would feel more autonomous. We also thought that autonomy would have a greater impact on the adjustment of the Buoyant than of the Beset.

The second dimension of program variation we investigated was the closeness boys felt to their staff, which is widely considered a prerequisite for successful treatment. Supposing that the Beset boys would have experienced a less stable home environment prior to their institutionalization, we reasoned that they would be more in need of supportive relationships with adults. Therefore, whether they felt close ties with adult staff members would have greater effect on their adjustment.

Another purpose of the present study is to refine the operational definition of the typology by incorporating information about the stability of anxiety and depression over time. We conceive of youths' Besetment/ Buoyancy at any point in time as a function of both their current situation and the personality that they bring to that situation. We supposed that some of the adolescents we observed in this study had a relatively stable level of Besetment/ Buoyancy while others did not. The former can reasonably be considered types of delinquents and we expect our hypotheses to hold for this group. This facet of the unstable youths' personality is not consistent enough to justify classifying them on our typology. 


\section{METHOD}

\section{SAMPLE}

The data are from a broader longitudinal investigation of peer influence in juvenile correctional institutions. The sample consisted of 306 adjudicated delinquent boys who entered one of two public or two private residential institutions in Michigan some time between September 1982 and October 1983. The typical resident had been arrested for two or more felony offenses. The average length of stay at these institutions is twelve months, and all of the institutions are open rather than secure.

The treatment program at all four institutions is Positive Peer Culture (Vorrath \& Brendtro, 1985), a heavily group-oriented approach. Youths live in groups of 9 to 12 members. Members of a group are together throughout the day for meals, school, recreation, and group therapy. They have little contact with members of other groups. Within each institution, assignment to groups is made according to the next available bed space, in effect a random assignment of boys to groups. Previous analyses have demonstrated that members of different groups are comparable to one another, after controlling for differences between institutions (Osgood et al., 1985).

\section{DATA COLLECTION}

This investigation takes advantage of three waves of data collection. Interviews were conducted with the youths within 10 days of their arrival at the institutions (initial interview), after they had been at the institutions for four months (interim interview), and shortly before their release. The youths were interviewed individually by a member of the research staff in a room set aside for individual testing.

Of the 370 youths who were invited to participate in the study and who stayed at the institution for at least four months, 335 or $90.5 \%$ completed an initial interview. Four months later, all but 9 of them were interviewed a second time, and 5 of these 9 were later 
interviewed before their release. For the release wave, data are available for 306 of the boys. In total, 18 youths could not be interviewed at this wave because they were released or transferred without our being notified, 4 truanted and were not located, and 3 more declined to participate further. Nevertheless, $81 \%$ of the eligible youths were interviewed at all three waves.

\section{MEASURES1}

Besetment/Buoyancy. This characteristic was measured in a manner similar to that described by Gold and Mann (1984). The measure was composed of three subscales: somatic symptoms of anxiety (Gold \& Mann, 1984), the trait anxiety subset of the state-trait anxiety scale (Spielberger, Gorsuch, \& Lushene, 1970), and the Center for Epidemiological Studies depression scale (Radloff, 1977). The youths completed the measure during the initial and release interviews. We totaled the standardized scores of the three subscales to assign each respondent a Besetment/ Buoyancy score for each wave. Its internal reliability, gauged by Cronbach's alpha, equaled .80 at intake and .77 at release.

In most of the analyses that follow we take advantage of the continuous nature of the measure of Besetment to increase the power of tests of our hypotheses. We treat Besetment/Buoyancy as a dichotomy when we compare the background characteristics of the Beset and Buoyant and in tests of interaction effects. It should be kept in mind, however, that Rubinstein's data indicate that findings based on the continuous score would undoubtedly hold if the sample had been dichotomized instead; but the findings would be statistically less precise. Generalizability from the continuous to the typological is important because, while the continuous variable is useful for statistical work, actually sorting delinquents for differential treatment implies categorization.

Components of program. Measures reflecting the characteristics of the groups to which the youths belonged came from responses to anonymous questionnaires given to all group members who were willing to participate in this phase of the 
study, including boys who were not in our focal sample that was interviewed. These questionnaires were administered three different times at six-month intervals, starting shortly after the time the first of the focal sample was admitted. An average of 9 members per group completed the questionnaires, and the overall response rate was $91 \%$. Group characteristics were scored as the mean across the group's members.

In order to explore the influence of the group experience, we took into account the characteristics of respondents' groups both when they entered the group and after they had been there for several months. For the former period, we used those measures that were obtained in the interval from four months before to two months after youths' initial interview. These indicated what the group was like when the youths arrived. Because these measures were taken well before the interim interview, there is little chance the measures of group characteristics were influenced by respondents' adjustment at the institution. Similarly, group-level data collected again four months later provided information about the characteristics of the groups well before youths were released.

Two measures of group functioning were of interest for this study: group autonomy and the group's ties to the staff. The group autonomy scale consisted of 17 items that asked group members how much independence and responsibility they felt they had and whether they felt free from coercion by the staff and their group. The Cronbach alpha for this scale averaged .85 over the three waves. The group's ties to the staff consisted of three items reflecting how close members of the group felt to their staff. For instance, one item asked "How close are you to the staff people here who you know best?" The Cronbach alpha for this scale averaged .79. Reliabilities for these measures were calculated with groups rather than individuals as the unit of analysis.

Psychological reflections of program components. Feelings of autonomy and closeness to the staff were measured at the level of the individual with the same items employed in the groups' questionnaire. Alpha for autonomy at the interim interview equaled .79; this measure was not taken at the release interview. 
The measure of individuals' "ties to the staff," available from both the interim and release waves, had an average alpha of .67.

Adjustment to the institution. Four measures from the interim and release interviews reflected different facets of adjustment. The first assessed the extent of the respondents' satisfaction with the institution. Institutional satisfaction was measured at both at interim and release, with an average alpha of .66.

The second adjustment scale measured residents'willingness to support a counterculture of opposition to institutional authority. Adapted from the work of Wheeler (1961) and Schwartz (1970), it consisted of fictional vignettes about other residents breaking institutional rules. Respondents indicated whether they would support others in breaking the rules, inform the staff, or try to remain neutral. The alpha for this index, which was administered only at the interim interview, was .73.

The third aspect of institutional adjustment we considered is delinquent values. At each wave, respondents were asked how much they would admire a person doing each of a set of activities, some delinquent, some conventional, and some neutral. High scores on the scale reflect admiration for those engaging in delinquent activities and a lack of admiration for those engaging in conventional activities. Alphas for this scale averaged .68 over the three interviews.

The fourth indicator of adjustment was the amount of delinquent activity in which respondents had been engaged while in the institution. The boys reported how many times in the preceding two months they had committed a variety of offenses, such as theft or gambling. We inquired about eleven such acts at both the interim and release interviews. Cronbach's alpha for these items equaled .78 at both administrations.

Two other outcomes may be considered official indicators of the boys' adjustment: graduating successfully (as opposed to being "escalated" to a more secure placement, absconding, or being released for administrative reasons) and the length of time the boys spent in the institution, provided that they did graduate successfully or were released for administrative reasons. Data for these two outcomes were obtained from institutional records. 


\section{RESULTS}

This presentation of results is divided into three sections. The first addresses the validity of our measure of Besetment and develops the distinction between respondents whose Besetment/ Buoyancy was stable versus unstable. In the second section, we compare the background characteristics of stable and unstable Buoyant and Beset respondents. Finally, we document the differential effects of the institutional programs on stable Beset and Buoyant boys and trace these to components of the program.

\section{VALIDITY AND STABILITY OF BESETMENT/BUOYANCY}

Recall that Rubinstein (1986) found that independent ratings by caregivers distinguished reliably between Beset and Buoyant delinquents. Our own data also include others' assessments of boys' characteristics. Fellow group members were asked, for example, to nominate those boys in the group "who really try to deal with their problems" or "who don't care about others." Beset youth were less often nominated in any of the six positive categories - notably as being popular $(p=.009)$ - and more often in the four negative ones. An overall index of positive and negative categories differentiated the two types significantly $(p=$ .02). Thus Besetment/Buoyancy does not seem to be merely a mode of responding to an interview; it seems to be manifest in public behaviors as well. Furthermore, the impression the Beset boys made on their peers appears to characterize them as lacking in the social skills that prompted Hewitt and Jenkins to label them "unsocialized."

The correlation between the boys' scores on Besetment/ Buoyancy at admission and at release was .37 , statistically significant at $p<.01$. The magnitude of this correlation indicates that Besetment/Buoyancy is unstable among a substantial number of boys in this study over this period of approximately one year. (This correlation is markedly lower than the .54 found over 16 months with the same measure among youth in Gold and Mann's [1984] study of alternative schools.) Before investigating 
the backgrounds and differential effects of treatment on the two types of delinquents, we thought it necessary to exclude those boys whose Besetment was less an enduring component of their character than a response to the immediate situation.

We used the reliability of the measure as our guide in assessing stability. The measure's reliability provides a basis for predicting what score a youth would be expected to receive at release, given his score at admission, simply as a consequence of regression to the mean. Change should be gauged relative to this expected score rather than the observed score at intake. If stability were assessed relative to initial observed scores, there would be a bias toward classifying extreme scores as unstable and moderate scores as stable. The formula we used for our calculations was predicted (i.e., estimated true) score $=$ intake mean $+($ alpha $\times$ [intake score - intake mean]).

Since the value of Cronbach's alpha for the intake score was .79 , then each student's score at release could be expected to deviate from the intake mean by $79 \%$ of his intake score's deviation from the intake mean. This calculation embodies the assumption of regression to the mean-that lower intake scores would increase over time and higher intake scores would decline.

Respondents whose actual Besetment/Buoyancy scores at release fell within one standard deviation-nine points - of their estimated true score were classified as stable. This group included 199 or $65 \%$ of the 306 boys who had been interviewed at intake and release. Thus we considered about two-thirds of these heavily delinquent boys to be stable enough on this dimension to meaningfully type them as Buoyant or Beset.

Next we present evidence for the efficacy of this method of identifying the stable Beset/Buoyant delinquents. Empirical support for the validity of our definition of stability is provided first by the two general quality-of-life questions included in both the intake and the release interviews. One was "How are you feeling about your life as a whole these days?"; the other, "How happy are you these days?" These two items were combined into a scale of well-being (average alpha $=.65$ ). Since these two 
questions were directed at a respondent's feelings toward his immediate circumstances - they followed a series of open-ended questions about what good and bad things have been happening "lately"-the well-being scale served as a measure of a boy's short-term, situational evaluation of himself and his life.

We found that the correlation between Besetment/Buoyancy and well-being at intake was significantly higher $(\mathrm{p}<.05$, by $\mathrm{r}$ to $\mathrm{z}$ transformation) among the unstable $(r=-.46)$ than among the stable $(r=-.25)$. This is consistent with our assumption that the Besetment/Buoyancy scores of unstable respondents reflected responses to the current situation rather than their personalities. At release, the correlation between well-being and Besetment/ Buoyancy was still stronger among the unstable, but not significantly so. The larger difference at intake was to be expected if the intake situation had a more powerful effect on depression and anxiety than did release. Our data indicate that this was the case: The average Besetment / Buoyancy at intake was 6.2 points higher $(\mathrm{p}<.01)$ than the average at release; while the average at release was only 0.1 points higher than the average of scores gathered in a fourth interview six months after release.

Perhaps the most telling support for the classification of stability may be found in the autocorrelations of Besetment/ Buoyancy in three of the panel's waves, presented in Table 1. Due to the way in which stability is defined, the correlation between intake and release Besetment/Buoyancy is automatically higher among the stable than among the unstable (.77 versus .23). More striking is that Besetment/Buoyancy at the time of the follow-up, which was not used to construct the stability classification, was significantly more highly correlated with the two earlier measures among the stable than among the unstable.

Having thus distinguished between the delinquents stable and unstable in their Besetment, we sorted the stable ones into Beset and Buoyant types for the purpose of some of our analyses. We divided the boys into 101 Buoyant and 98 Beset based on the median of the sum of their intake and release Besetment scores (the median was 72 in the possible range of 30 to 120). 
TABLE !

Cross-Time Correlations in Besetment: Stable and Unstable

\begin{tabular}{|c|c|c|}
\hline & \multicolumn{2}{|c|}{ Stable $(N=160)$} \\
\hline & Intake Besetment & Release Besetment \\
\hline \multirow{3}{*}{$\begin{array}{l}\text { Release Besetment } \\
\text { Followup Besetment }\end{array}$} & .77 & \\
\hline & .60 & .59 \\
\hline & \multicolumn{2}{|c|}{ Unstable $(\mathrm{N}=87)$} \\
\hline Release Besetment & .23 & \\
\hline Followup Besetment & .35 & .39 \\
\hline
\end{tabular}

\section{DIFFERENCES IN}

\section{BACKGROUND CHARACTERISTICS}

More support for our method of identifying the stable Buoyant and Beset and sorting them into dichotomous types lies in its construct validity. There were certain ways in which the background characteristics of the consistently Beset youths were expected to differ from those of the consistently Buoyant. If their levels of anxiety and depression were more than temporary, then Beset and Buoyant boys would be expected to have had different experiences prior to their admission to the institution and the initial assessment of their Besetment/Buoyancy. We hypothesized that Beset youths would be more likely to come from broken homes, would have had more prior institutional placements, and would have committed more of their crimes alone. These differences were not expected among youths whose Besetment was not stable over time. Indeed, results indicate that these distinctions between Buoyant and Beset are greater among the stable than among the unstable. (See Table 2. The same cut-off 
TABLE 2

Key Differences: Buoyant-Beset for Boys with Stable and Unstable Scores

\begin{tabular}{llc}
\hline & $\begin{array}{c}\text { Stable } \\
(\mathrm{n}=199)\end{array}$ & \multicolumn{1}{c}{$\begin{array}{c}\text { Unstable } \\
(\mathrm{n}=107)\end{array}$} \\
\hline Mean Age & $0.28 * *$ & 0.10 \\
$\begin{array}{l}\text { Mean percent of crimes } \\
\text { committed alone }\end{array}$ & $-9.75 \% * * *$ \\
$\begin{array}{l}\text { Percent with prior } \\
\text { placements }\end{array}$ & $-16.3 \% * *$ \\
$\begin{array}{l}\text { \% living at home with } \\
\text { parents }\end{array}$ & $19.27 \% * * *$ \\
$\begin{array}{l}\text { \% living with mother } \\
\text { b living with fatherc }\end{array}$ & $14.42 \%$ & $-15.71 \%$ \\
\hline
\end{tabular}

a. Limited to the $\mathbf{2 9 3}$ who reported five or more offenses.

b. Natural mother or stepmother.

c. Natural father or stepfather.

$\star p<.10 ; * \star p<.05 ; * \star * p<.01$.

number was used to separate the Buoyant from the Beset among the unstable as among the stable.)

The percentage of the stable Buoyant living with parents exceeded the percentage of Beset with these living arrangements by a highly significant 19 percentage points; among the unstable, the 6 percentage point difference could easily have occurred by chance. The stable Buoyant were also significantly less likely to have conducted their delinquent activity alone than were the stable Beset. Moreover, we found that the Buoyant were significantly older than the Beset among the stable, consistent with our assumption that the Beset delinquents are more immature. There was no age difference between the Buoyant and the Beset among the unstable.

\section{EFFECT OF BESETMENT/BUOYANCY ON INSTITUTIONAL ADJUSTMENT}

We have hypothesized that the Beset/Buoyant typology would be associated with differential response to two aspects of 
experiences in the treatment program: feelings of autonomy and personal ties to the staff. Such differential response could occur through either of two processes. In the first, institutional experiences mediate between the typology and adjustment at the institution-one type or the other is more prone to have experiences that lead to poorer adjustment. In the second process, institutional experiences interact with typology-one type is more affected by a given experience than the other.

Since we had obtained individual and group-level measures of program features, we were able to estimate models of the effects of group norms and individual perceptions on measures of adjustment. These measures included both assessments of the autonomy and closeness to staff felt by the average member of the group to which a student belonged and assessments of each student's individual feelings of autonomy and closeness to the staff. ${ }^{2}$

The path diagrams in Figures 1 and 2 depict adjustment of only the stable types at interim and release as a function of their personal autonomy, which is itself a function a Besetment/ Buoyancy at intake and the relative autonomy sensed by the group prior to or early in the boys' stay. The figures on the paths are standardized regression coefficients indicating the size of the effect of one variable on the other. The coefficients in parentheses are the effects after the mediating variable, personal autonomy, is controlled. $R^{2}$ indicates the amount of variance of the measure of adjustment that is accounted for by the set of predictors.

As we had suspected, the less Beset boys tended to feel more autonomous. Since personal autonomy itself was a strong positive influence on adjustment at interim and release, the effect of Besetment/Buoyancy on the boys' institutional satisfaction, delinquent values, countercultural attitudes (measured only at interim), and delinquent behavior was mediated by the positive impact of Besetment/Buoyancy on personal autonomy: The more Beset adjusted less well partly because they felt less autonomous. It should be noted, however, that the group's norms concerning the amount of autonomy they experienced far outweighed boys'initial Besetment/Buoyancy in determining the amount of autonomy they experienced personally at interim. 


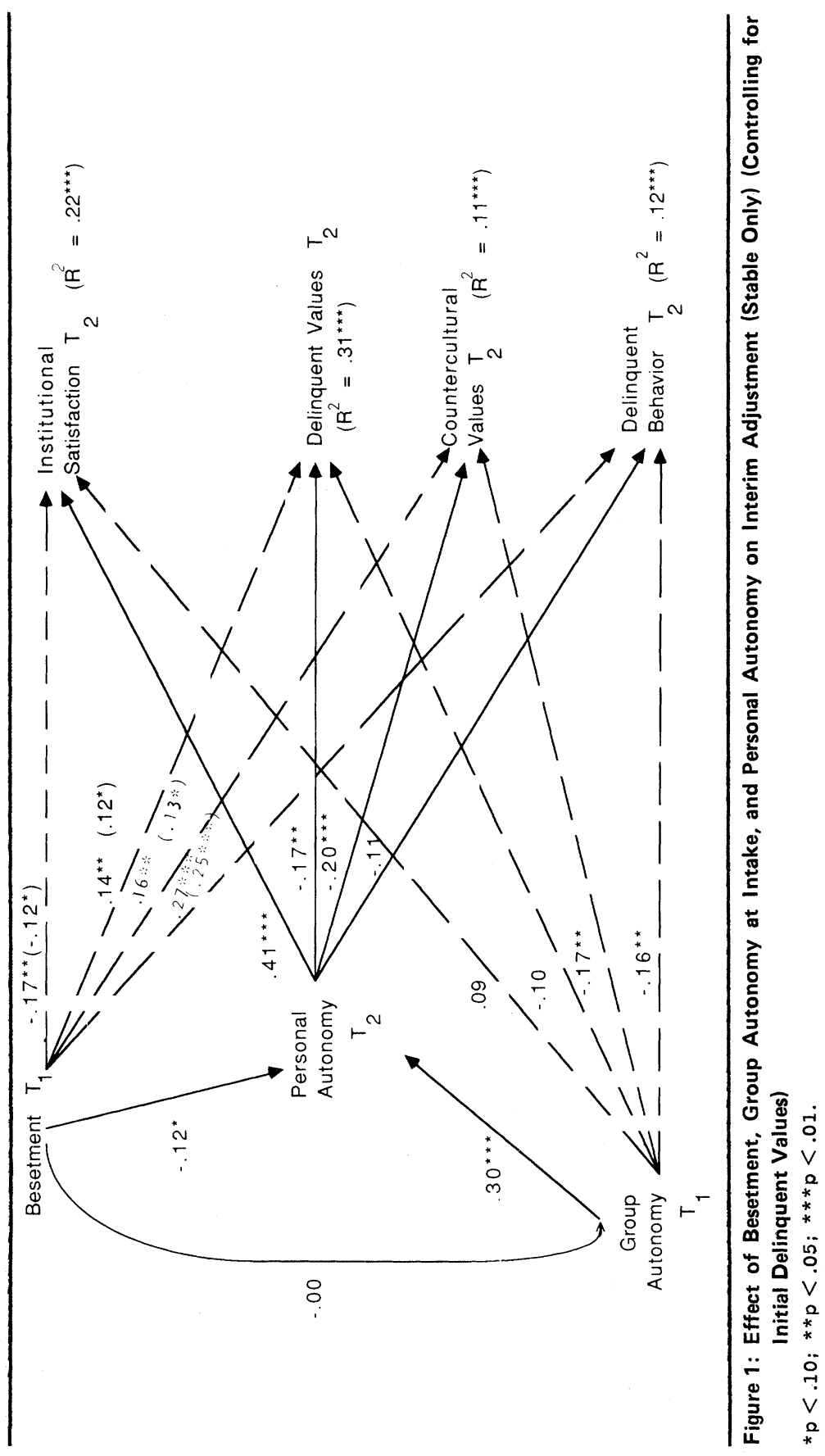




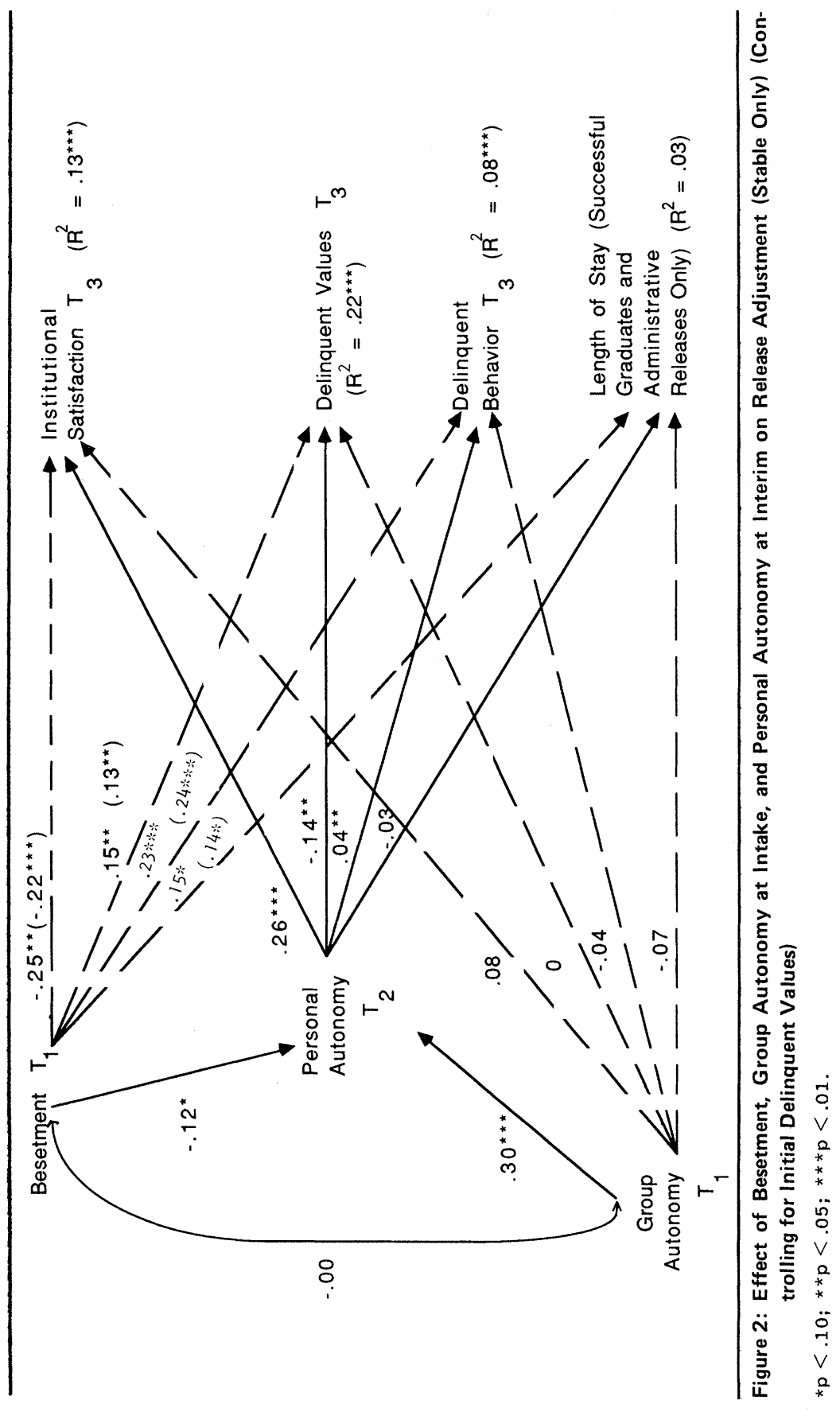


It is worth noting that not all the effects of initial Besetment/ Buoyancy on institutional adjustment were mediated by boys' feelings of personal autonomy. Even after accounting for personal autonomy, initial Besetment/Buoyancy was responsible for a significant amount of the variance in measures of adjustment at both the interim and release interviews.

Boys' feelings of closeness to their staff teams also had a markedly positive impact on their adjustment at the interim and release interviews (see Figures 3 and 4). However, Besetment/ Buoyancy did not work through staff ties in influencing adjustment because Besetment/Buoyancy had no reliable relationship to boys' feelings about staff. (Group ties to staff do work through individual staff ties in influencing adjustment.)

Having explored the mediating effects of autonomy and close ties to staff, we turned to their interactive effects. Here we were concerned with whether Beset and Buoyant types would be differentially affected even if they felt equally autonomous or equally close to staff.

In order to test these interactions, we used the dummy variable that divided the boys into 101 Buoyant and 98 Beset. All of the continuous variables were standardized (with respect to their distributions among the stable only). The terms for the interactions of Besetment / Buoyancy and personal autonomy and for the interactions of Besetment/Buoyancy and personal ties to staff are the products of a $0-1$ dummy variable and a standardized variable. Thus the coefficients for these interaction terms represent the difference in standardized slopes between the two groups.

For the most part, autonomy and ties to staff affected the adjustment of the two types of delinquents similarly, both after four months stay and at release. We did find three significant interactions $(\mathrm{p}<.10)$, however, all supportive of our hypotheses. As Figure 5 shows, a feeling of greater autonomy at interim was associated with more satisfaction with the institution at the time of release among the Buoyant type; autonomy at the interim was not related to Beset delinquents' satisfaction. Conversely, close ties to staff were significantly associated with less delinquent behavior of Beset delinquents at interim and release, but it was 


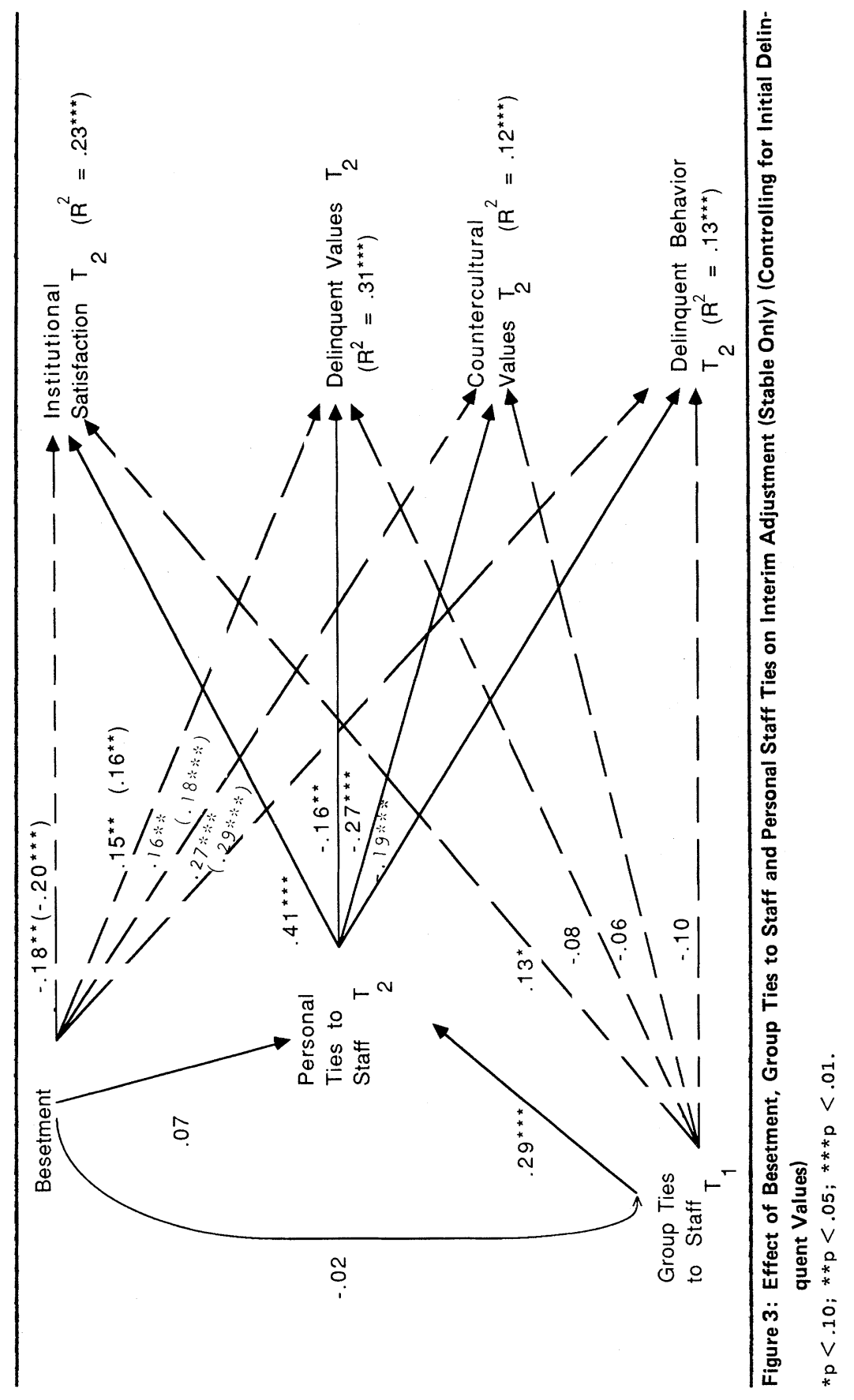




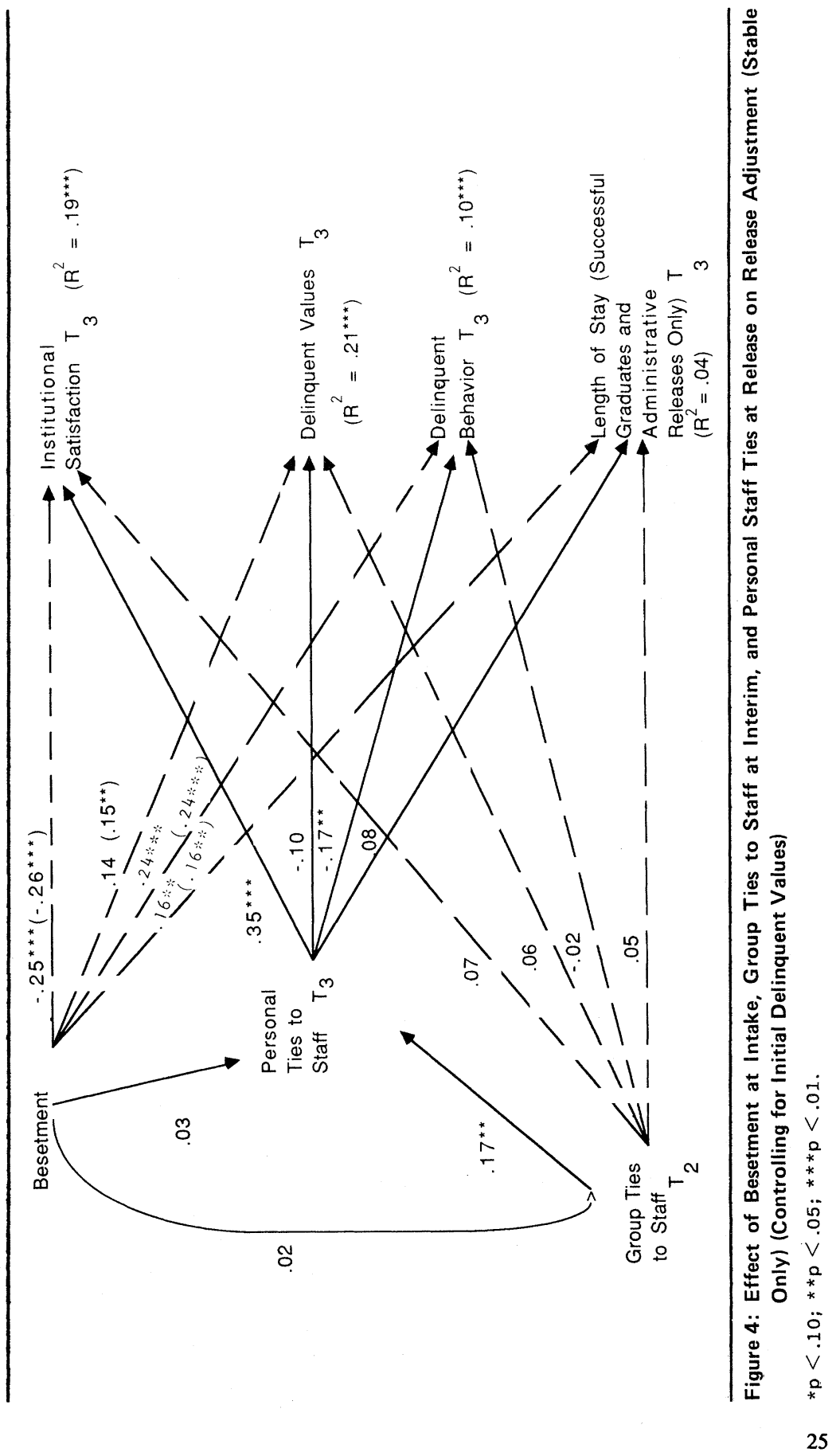




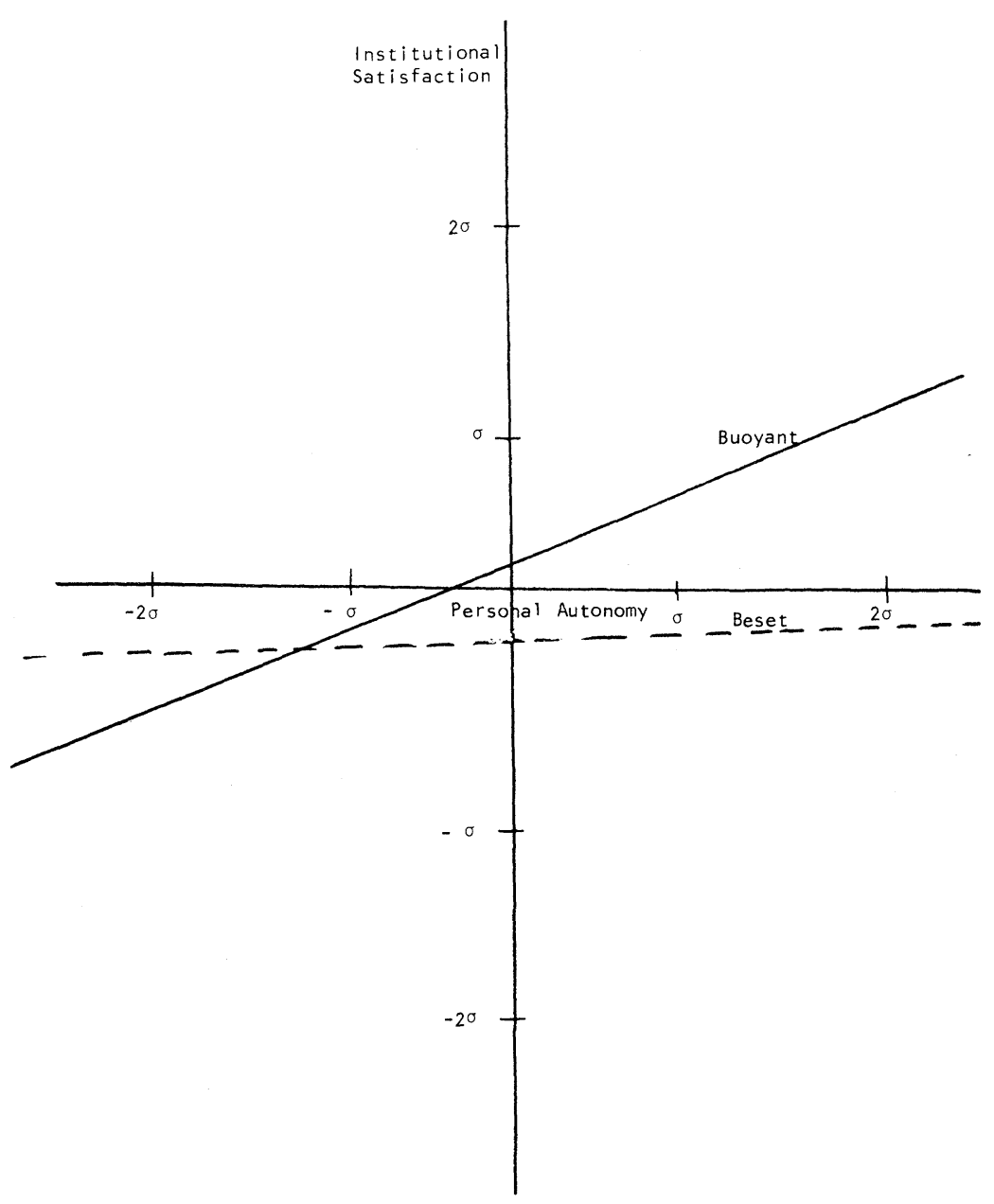

Figure 5: Relationship Between Personal Autonomy (Interim) and Institutional Satisfaction (Release) Beset and Buoyant (Stable Only)

NOTE: Holding initial group autonomy and delinquent values constant.

not related to the behavior of the Buoyant type. (See Figure 6 for the findings at four months.) Of the 14 possible tests of interactive effects of Besetment/Buoyancy with autonomy or staff ties on adjustment (four adjustment indexes at interim, three at release), 


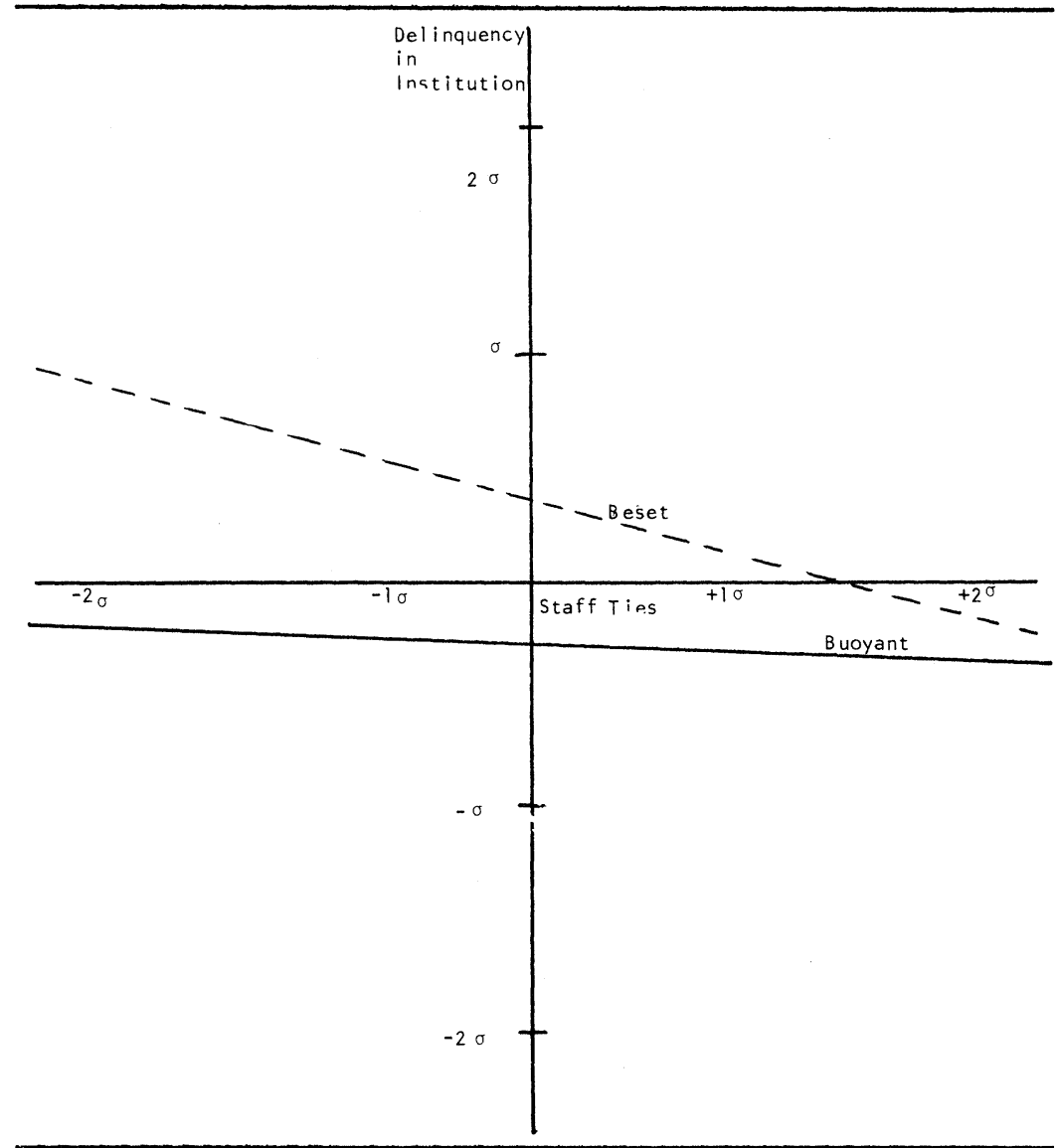

Figure 6: Relationship Between Staff Ties (Interim) and Delinquency (Interim): Beset and Buoyant (Stable Only)

NOTE: Holding initial group ties to staff and delinquent values constant.

11 were in the expected direction, 3 negligibly in the opposite direction. All of these 3 involved staff ties.

Finally, we sought to determine whether the kind of group in which a boy was placed affected his adjustment any differently if he was Beset rather than Buoyant. This is an eminently practical question: Does placing a Beset youth in a group with weaker staff ties affect his attitudes and behavior more than it would affect the attitudes and behavior of a Buoyant boy? If so, group assignments 
could be made on the basis of a boy's Besetment/Buoyancy (provided that it is known that his Besetment/Buoyancy is stable).

Searching for interactive effects of Buoyant/Beset with group characteristics also has some methodological significance. Group characteristics were measured with questionnaires answered by all the boys in a group and were almost entirely independent of any one Beset or Buoyant boy's perceptions. Thus if a group as a whole felt relatively close ties to its staff, it is likely that these ties were a social reality, that they were not solely in the perceptions of the individual boys. Further indication that these group characteristics were social realities resides in the fact that groups differed significantly in autonomy and the closeness of their ties to staff; that is, intergroup differences in means were significantly greater than intragroup differences among members. There is reason to believe then that autonomy and ties to staff are group properties, not only perceptions of individuals.

We found little evidence of interaction between Besetment/ Buoyancy and group norms about staff ties or autonomy. Only one such interaction is worthy of mention. Group ties to staff at intake led to less delinquent values at interim among the Beset, but not among the Buoyant. This finding, significant at the .05 level, was similar to the finding in Figure 6. This interaction was not significant at release, however.

Significant mediating and interaction effects were more prevalent and stronger in our data among the boys we have identified as stable. Replicating these analyses with the unstable youth, we found few of the relationships that appear among the stable.

\section{DISCUSSION}

These data from a longitudinal study of incarcerated boys indicate that a typology of delinquents based on their degree of anxiety and depression-Besetment/Buoyancy-is a useful one. The typology is related to experiences and behavior prior to incarceration, thus suggesting it has some promise for identifying 
different causal processes. It is also related to different responses to treatment programs, which has practical as well as theoretical implications.

The typological differences suggest a conception of the Beset delinquents as trying to cope with psychological problems whose origins are developmentally earlier than the problems of the Buoyant type, problems invested with feelings of basic insecurity. We have found that the Beset boys differed from the Buoyant boys prior to their incarceration: The Beset boys were younger at the time of their admission, suggesting an earlier onset of their delinquency. A greater proportion of the Beset boys had been separated from their parents and had been placed outside of their parents' home, and they reported committing more of their recent delinquent acts alone. In contrast, the Buoyant boys' delinquency may arise in response to issues, such as autonomy, that confront youth most sharply in our culture at adolescence.

These conceptions of the Beset and Buoyant types are parallel to the conceptions of the unsocialized and the socialized delinquents formulated by Hewitt and Jenkins (1947), Quay (1987), and others. Interpreting the typological difference between the Beset and Buoyant boys as a function of the maturity of their conflicts points to another similarity, between this typology and the work on "I-levels" of delinquents by Warren $(1966,1969)$. "I-level" refers to level of immaturity, and research generated by that approach has also proved fruitful for discovering differences in life-histories and in responses to treatment.

Additional methodological work is needed. One problem is that the source of almost all the data reported here is the boys themselves. That opens up the possibility that response biases account for the findings. The background characteristics on which we compared the Beset and Buoyant boys were selected to minimize this potential for distortion; they consist of reports of facts-age, family structure, out-of-home placements, and companionship in delinquency - not subject to distortion by a boy's mood at the time of the intake interview. In all likelihood, they represent boys' actual experiences prior to our assessment of their type. Nevertheless, further research should include observations by independent observers where possible. 
The practical significance of the Beset/Buoyant typology ultimately will lie in its utility for sorting out delinquents for the purpose of differential treatment. It has already been demonstrated that sorting exclusively on the basis of the assessment of Besetment / Buoyancy at intake differentiates those who are more and less likely to make a good adjustment to the institution after four months stay (Atwood et al., in press).

Obviously, sorting delinquents by types on the basis of their scores at release as well as at intake, as we have done here, has little immediate practical significance because it requires information that won't be available at the time plans for intervention must be made. Even so, identification of the stable Beset and Buoyant types and an exploration of their differential responses to institutional programs may prove useful in the long run. If the two types do indeed respond differently, that will tend to confirm the validity of the typology and warrant efforts to refine measures for typological sorting.

Further research will help to establish the categorical cutpoint on the Besetment/Buoyancy continuum. But the optimal cutpoint will depend not only on how sharply the division distinguishes the types in terms of background characteristics and responsiveness to a particular treatment. The conditions and quality of measurement will also have to be considered, as will the resources available in each instance for treating certain numbers of Beset or Buoyant youth.

Our procedures for dividing the sample into stable and unstable groups proved effective for demonstrating that the classification is more valid for stable respondents than for others. Nevertheless, our choice of one standard deviation from the estimated true score as the criterion for stability is arbitrary. Thus our classification of two-thirds of the sample as stable is not necessarily an accurate estimate of the proportion of the population that could be meaningfully typed. Further research will be needed to determine the optimal division between stable and unstable.

There were few statistically significant interaction effects that would indicate differential responses to features of the treatment program. Nevertheless, the overall consistency of the data with 
our conceptions of the two types suggests that they have not turned up merely by chance. Feelings of autonomy were more conducive to the adjustment of the Buoyant youth; and close ties to staff proved more beneficial for the Beset. As we have pointed out, the Beset have had less stable relationships with their parents. Having a close relationship with one or more of the staff members who care for them might ameliorate their insecurity and facilitate their institutional adjustment. The Buoyant type, on the other hand, seems to be socio-emotionally more mature than the Beset, concerned with the typical adolescent issue of autonomy. Their freedom of action was severely constrained by incarceration, placing them under the close surveillance and control of adults. Having some degree of autonomy within these institutional constraints facilitated some facets of their adjustment, while autonomy had negligible effects on the Beset delinquents. It should also be recalled that the Beset boys were prone to feel less autonomous than the Buoyant.

These findings indicate that the Beset/Buoyant typology of delinquents merits further investigation. There are a number of important questions that should be addressed. Longitudinal studies are needed to determine the child-rearing antecedents of Besetment/Buoyancy, including parenting styles and discontinuity of caregiving. Content analyses of detailed descriptions of delinquent behavior might prove useful for illuminating differences between the two types in the nature of their delinquent involvement. Thus far, our own investigations have discovered no distinction in delinquent activity except that the Beset boys commit a larger proportion of their delinquency alone. Finally, theory-based field experiments would be appropriate as the next step to determining which treatments are most effective for each type.

\section{NOTES}

1. Copies of measures may be obtained by writing to Martin Gold, Institute for Social Research, Box 1248, Ann Arbor, MI 48106. 
2. Since personal autonomy was not assessed at release, interim personal autonomy and initial group autonomy were controlled in the first set of models, while group staff ties at interim and individual ties at release were controlled in the second set. Initial delinquent values are controlled in all models.

\section{REFERENCES}

Atwood, R., Gold, M., \& Taylor, R. (in press). Journal of Consulting and Clinical Psychology.

Atwood, R., \& Osgood, D. W. (1987). Cooperation in group treatment programs for incarcerated adolescents. Journal of Applied Social Psychology, 17, 969-989.

Cloward, R. A., \& Ohlin, L. R. (1960). Delinquency and opportunity. New York: John Wiley.

Eysenck, H. (1970). Crime and personality. London: Granada.

Field, E. (1967). A validation study of Hewitt and Jenkins's hypothesis. Types of delinquent and home background. London: HMSO.

Gold, M., \& Mann, D. W. (1972). Delinquency as defense. American Journal of Orthopsychiatry, 42, 463-479.

Gold, M., \& Mann, D. W. (1984). Expelled to a friendlier place. Ann Arbor, MI: University of Michigan Press.

Gold, M., \& Petronio, R. J. (1980). Delinquent behavior in adolescence. In J. Adelson (Ed.), Handbook of adolescent psychology (pp. 495-535). New York: John Wiley.

Hare, R. (1970). Psychopathy: Theory and research. New York: John Wiley.

Hewitt, L. E., \& Jenkins, R. A. (1947). Fundamental patterns of maladjustment. Springfield, IL: State Printer.

Hindelang, M. J., \& Weis, J. G. (1972). Personality and self-reported delinquency. Criminology, 10, 268-294.

Hunt, S. M., Jr., Singer, K., \& Cobb, S. (1967). Components of depression. Archives of General Psychology, 16, 441-447.

Kaplan, H. B. (1980). Deviant behavior in defense of self. New York: Academic Press.

Lykken, D. (1957). A study of anxiety in the sociopathic personality. Journal of Abnormal and Social Psychology, 55, 6-10.

Martin, F. P., \& Osgood, D. W. (1987). Autonomy as a source of pro-social influence among incarcerated adolescents. Journal of Applied Social Psychology, 17, 97-107.

McCord, W., McCord, J., \& Zola, I. K. (1959). Origins of crime. New York: Columbia University Press.

Megargee, E. I., \& Bohn, M. J. (1979). Classifying career criminal offenders: A new system based on the MMPI. Beverly Hills, CA: Sage.

Osgood, D. W., Gruber, E., Archer, M. A., \& Newcomb, T. M. (1985). Autonomy for inmates: Counterculture or cooperation? Criminal Justice and Behavior, 12, 71-89.

Quay, H. C. (1964). Dimensions of personality in delinquent boys as inferred from the factor analysis of case history data. Child Development, 35, 479-484.

Quay, H. C. (1987). Patterns of delinquent behavior. In H. C. Quay (Ed.), Handbook of juvenile delinquency (pp. 118-138). New York: John Wiley.

Radloff, L. S. (1977). The CES-D scale: A self-report depression scale for research in the general population. Journal of Applied Psychological Measurement, 1, 385-401. 
Rubinstein, D. M.(1986). The Buoyant and the Beset: A typology of juvenile delinquents. Unpublished doctoral dissertation, University of Michigan, Ann Arbor.

Schwartz, B. (1970). The influence structure of a correctional community. Unpublished doctoral dissertation, University of Pennsylvania.

Shinohara, M., \& Jenkins, R. L. (1967). MMPI study of three types of delinquents. Journal of Clinical Psychology, 23, 156-163.

Shore, M., \& Massimo, J. (1969). Five years later: A follow-up study of comprehensive vocationally oriented psychotherapy. American Journal of Orthopsychiatry, 39, 769-773.

Spielberger, C. D., Gorsuch, R. L., \& Lushene, R. E. (1970). Manual for the State Trait Anxiety Inventory. Palo Alto, CA: Consulting Psychologists Press.

Vorrath, H. H., \& Brendtro, L. K. (1985). Positive peer culture (2nd ed.). Hawthorne, NY: Aldine.

Warren, M. Q. (1966). Classification of offenders as an aid to efficient management and effective treatment. Sacramento: California Youth Authority.

Warren, M. Q. (1969). The case for differential treatment of delinquents. Annals, 381, 47-59.

Wheeler, S. (1961). Socialization in correctional communities. American Sociological Review, 66, 697-712. 